\section{Fighting foot-and-mouth}

\section{from a Correspondent}

THE Animal Virus Research Institute celebrated the completion of 50 years of research on foot-and-mouth disease at Pirbright by holding a symposium on September 26 and 27.

The changes in the world situation were reviewed by three speakers. Dr J. G. van Bekkum (State Veterinary Institute, Lelystad, Netherlands) presented the tables of prevalence of the disease in European countries in the last 50 years. During the major waves of disease-for example, in 1937/8 and in $1951 / 2$-there were as many as 370,000 outbreaks in countries such as France and Germany. The development of the tongue tissue vaccine by Frenkel had made possible the introduction of prophylactic vaccination and campaigns were begun in Holland in 1952 and, within the next ten years, in France and Belgium. In each country the number of outbreaks fell dramatically, to under $10 \mathrm{yr}^{-1}$. There had been problems in relation to immunisation of pigs but these were being overcome and, in the recent outbreak in France, vaccine had played an important part in control. Europe still remained at risk through importation and through possible spread of the disease from Eastern Mediterranean countries but prospects for the control of ultimate eradication from Western European countries were good.

Dr J. H. Graves (Plum Island Animal Disease Research Laboratory, New York) dealt with current problems in the control of the disease in the Americas. In spite of the great efforts which have been made in extensive vaccination campaigns, results have not been as good as would have been expected on the basis of the European experience. A particularly difficult problem was the control of potency of vaccines used in the field and it was here that the work of the Pan American Foot-and-Mouth Disease Centre in Rio de Janeiro might be expected to influence the situation. This centre had already run many courses for laboratory workers in various countries in South America and, as a result, diagnostic methods had been improved and standardised. Similar action is now being taken on vaccine potency control. Dr Graves also referred to the new risks which were posed by the planned Pan-American Highway. Plans were being discussed for quarantine zones to prevent spread of the disease northwards.

Dr J. B. Brooksby (Pirbright) drew attention to the very uneven progress in control of the disease in countries in Asia and Africa. Extensive cam- paigns have been carried out in the Soviet Union but the statistical information available is slight. In many other regioris limited campaigns have begun. Perhaps the most encouraging of these were in relation to disease-free zones. A good example was in Kenya, where a start had been made with a limited number (fewer than 400,000 ) of animals and gradually extended as the campaign was shown to be a success. The zone in which the disease was not controlled included nearly two million animals. Though the total number of animals so far involved in Asia and Africa was trivial in comparison to the population, it was in such schemes that lay the greatest hope for ultimate control of the disease and the development of useful programmes for livestock improvement.

In another session, the biosynthesis of the virus and the structure of the virus particle in relation to its antigenic properties were reviewed by members of the biochemistry department of the institute. A paper by Dr K. M. Cowan (Plum Island Animal Disease Research Laboratory, New York) carried the studies of virus properties into the field of vaccines. The properties of two plaque variants isolated from cultures of virus of type Asia 1 in BHK cells were described. Selection occurred during routine passage, the large plaque variant being predominant in monolayer culture, where as the small plaque variant was favoured by growth in suspended cells. The small plaque variant was antigenically deficient in serological tests and also in its capacity to immunise cattle. This finding emphasised the practical importance of the method of culture of the virus for vaccine production.

\section{The arithmetic of destruction}

\section{by David Davies}

RARELY does the arithmetic of strategic nuclear weaponry surface for public discussion: words such as superiority, sufficiency and imbalance are reckoned to be all that a layman, or for that matter a politician, should require. All the more welcome then, is a recent pamphlet Offensive Missiles by Kosta Tsipis of the Stockholm International Peace Research Institute (Stockholm Paper 5). The author tries to form numerical estimates of destruction capabilities of the US and Soviet land-based missiles and concludes that the United States has been, is and will continue to remain well ahead.

As long as the accuracy of missiles was inadequate to guarantee that the opposition's missile silos would be wiped out by a pre-emptive strike, it was foolish for a potential aggressor to target missile bases extensively, since the counterpunch aimed at cities could be so massive. Thus for many years targetting doctrine was centred on the destruction by both sides of cities. Gradually, however, the acquisition of missiles with higher accuracies capable of splitting in flight into several reentry vehicles (MIRVs) each with its own target has enabled the possibility to be reconsidered of taking out all silos at each 'farm' and all farms simultaneously. But this operation depends crucially on accuracies and reilabilities being sufficient to ensure that few, if any, opposing missiles remain serviceable. That this is now on the cards is clear from, among other things, the declaration of the US Secretary of Defence, Mr Schlesinger, of the US government's intention to go for a counterforce capability.

Warheads can destroy missiles in their silos by a variety of methods: the overpressure from a blast is perhaps the most damaging effect and consequently silos are often hardened to withstand pressures up to several hundred pounds per square inch. Let $H$ be the hardening pressure. In dealing with destruction probabilities the yield in megatons $(y)$ and the circular error probability $(C E P)$ in nautical miles appear in the ratios $y^{\frac{3}{3}} /(C E P)^{2}$ which call $K$, the lethality.

Then if $n$ warheads are aimed at the same target, the probability of demolishing it with at least one warhead is

$$
P=1-\exp \left\{\frac{K n}{2 H^{\frac{3}{3}}\{f H\}^{\frac{2}{3}}}\right\}
$$

The function $f(H)$ is slow varying and for $H$ in the range $100-1,000$ pound per square inch is roughly 0.15 . Thus, for example, to have a probability of $90 \%$ of destroying a silo hardened to 1,000 p.s.i. a value of $K n$ of 71 is needed.

Tsipis makes the important point that countersilo capability of a strategic nuclear force is thus dependent on the product $K n$ summed over all missiles. This should allow us to calculate the relative abilities of the United States and Soviet Union to annihilate each other's missile forces. The figure shows how the two sides stand in 1974.

The weakest element in all this is knowledge of the accuracy of the reentry vehicle as reflected quadratically in the CEP. The US values are fairly easily inferred from the open literature, but can the Soviet values-in all cases inferior to those of the US-be relied upon? Tsipis follows a policy of minimising the difference between Soviet and US accuracies: the Soviet value is the most optimistic, the US value the most pessimistic supportable by published figures. This may be sound policy, but it will raise a fow eyebrows that Soviet missiles are so inferior to 